\title{
Primary Biliary Cirrhosis-related Autoantibodies in a Large Cohort of Italian Patients with Systemic Sclerosis
}

\author{
ILARIA CAVAZZANA, ANGELA CERIBELLI, MARA TARABORELLI, MICAELA FREDI, GARY NORMAN, \\ ANGELA TINCANI, MINORU SATOH, and FRANCO FRANCESCHINI
}

\begin{abstract}
Objective. To analyze the prevalence, associations, and fine specificity of autoantibodies to primary biliary cirrhosis (PBC)-associated antigens (MIT3, Sp100, and gp210) in a cohort of Italian patients with systemic sclerosis (SSc).

Methods. Sera samples from 201 patients with SSc were tested for antibodies to MIT3, gp210, and Sp100 by ELISA (the PBC screen). Anti-MIT3-positive sera were studied for IgG or IgA isotypes. All sera were analyzed by indirect immunofluorescence on HEp-2 cells and on rodent kidney/stomach/liver tissue sections in order to detect antinuclear and antimitochondrial antibodies (AMA). SSc was selected by American College of Rheumatology criteria and classified based on LeRoy's criteria.

Results. Forty-three (21.4\%) sera samples were positive for PBC screen antibodies. Anti-MIT3 antibodies were detected in 36 samples, anti-Sp100 in 5, and anti-gp210 in 1 sample. The other 3 PBC screen-positive samples showed no specificity for the single antigens. PBC screen-positive patients more frequently showed a limited cutaneous SSc subtype $(\mathrm{p}=0.04)$, anticentromere antibodies (ACA; $p=0.0013)$, elevated alkaline phosphatase (ALP) $(\mathrm{p}<0.0001)$, PBC ( $\mathrm{p}=0.002)$, and AMA $(\mathrm{p}=0.008)$. Teleangiectasia and calcinosis were less frequent in this group of patients. $\operatorname{IgG}+\operatorname{IgA}$ anti-MIT3-positive patients had higher prevalence of AMA $(p=0.0035)$, diagnosis of PBC $(p=$ $0.014)$, and increased ALP ( $\mathrm{p}=0.039)$, all considered biochemical markers of severe liver disease. Conclusion. PBC screen antibodies were detected in $20 \%$ of patients with SSc, strongly associated with ACA. ACA+/PBC screen+ patients had higher risk of developing PBC or elevation of ALP. (First Release Sept 15 2011; J Rheumatol 2011;38:2180-5; doi:10.3899/jrheum.110167)
\end{abstract}

Key Indexing Terms:

PRIMARY BILIARY CIRRHOSIS SYSTEMIC SCLEROSIS S ANTICENTROMERE ANTIMITOCHONDRIAL ANTIBODIES ALKALINE PHOSPHATASE

Primary biliary cirrhosis (PBC) is a chronic autoimmune cholestatic liver disease, characterized by slow and indolent progression to liver failure. It can frequently be associated with autoimmune diseases such as Sjögren's syndrome, autoimmune thyroiditis, and systemic sclerosis (SSc). It has been reported that $2 \%-3 \%$ of cases of SSc have coexisting $\mathrm{PBC}^{1,2,3}$. The serological hallmark of $\mathrm{PBC}$ is presence of antimitochondrial antibodies (AMA), detected in about $90 \%$ of cases, occurring long before clinical onset of the disease $^{4,5}$. Nevertheless, AMA do not predict the severity of

From the Rheumatology Unit, Spedali Civili, University of Brescia, Brescia, Italy; Department of Oral Biology, and Department of Medicine, University of Florida, Gainesville, Florida, USA; and Inova Diagnostics, San Diego, California, USA.

I. Cavazzana, MD, Chair, Rheumatology Unit, Spedali Civili, University of Brescia; A. Ceribelli, MD, Department of Oral Biology, University of Florida; M. Taraborelli, MD; M. Fredi, MD, Rheumatology Unit, Spedali Civili, University of Brescia; G. Norman, MD, Inova Diagnostics; M. Satoh, MD, PhD, Department of Medicine, University of Florida; A. Tincani, MD; F. Franceschini, MD, Rheumatology Unit, Spedali Civili, University of Brescia.

Address correspondence to Dr. I. Cavazzana, Rheumatology Unit,

Spedali Civili, Piazzale Spedali Civili 1, 25100 Brescia, Italy.

E-mail: ilariacava@virgilio.it

Accepted for publication June 9, 2011.
PBC or any clinical subset of disease ${ }^{6}$. Antibodies to multiple nuclear dots, including promyelocytic leukemia and Sp100 antigens ${ }^{7}$, and antibodies recognizing different peptides of nuclear pore complex, such as gp210 or p62, are also currently considered serological markers of the disease $^{8,9}$ associated with severe prognosis ${ }^{8,9,10,11}$. Recently, an ELISA has been developed to detect AMA using a combination of 3 mitochondrial antigens: MIT3 (pyruvate dehydrogenase complex, branched chain oxo-acid dehydrogenase complex, and oxo-acid glutarate dehydronase complex), anti-Sp100, and anti-gp210 ${ }^{12}$. The combination of anti-MIT3 and anti-Sp100 has been shown to retain high sensitivity and specificity for a diagnosis of clinically evident $\mathrm{PBC}$ in $\mathrm{SSc}^{2}$. The aim of our study was to analyze the prevalence, clinical associations, and the isotype specificity of antibodies to MIT3, Sp100, and gp210 in a cohort of Italian patients with SSc. Considering the diagnosis of $\mathrm{PBC}$ as the "gold standard," we assessed the sensitivity and specificity of anti-MIT3 antibodies.

\section{MATERIALS AND METHODS}

Patients. Among 440 consecutive patients with SSc followed at our institution (Rheumatology Unit, Brescia, Italy) since 1983, we analyzed clinical

Personal non-commercial use only. The Journal of Rheumatology Copyright (c) 2011. All rights reserved. 
and laboratory data of 201 subjects whose sera were available for autoantibody analysis. All patients gave their informed consent for the study. More than $99 \%$ of patients were Caucasians of Italian ancestry. SSc was diagnosed according to the American College of Rheumatology criteria ${ }^{13}$ and classified according to the LeRoy criteria ${ }^{14}$ in order to define the different clinical subsets. Patients were routinely evaluated following the standard recommended guidelines ${ }^{15}$ : active interstitial lung disease was diagnosed on high-resolution computer tomography and/or bronchoalveolar lavage findings; pulmonary arterial hypertension (PAH) was defined using Doppler echocardiography, performed at least yearly, as screening test and right heart catheterization as the gold standard, as recommended ${ }^{15}$. A total of 23 PBC cases were followed in our clinic. Among 201 patients considered in this report, a liver biopsy was performed in 8: a histological diagnosis of PBC was confirmed in 7 cases, and 1 case of hepatitis C virus-related cirrhosis was detected and not considered in the analysis. A diagnosis of PBC was made globally in 8 patients combining laboratory, immunological, and/or histological data according to the European Association for the Study of the Liver Clinical Practice Guidelines ${ }^{16}: 6$ cases with anti-PBC screen antibodies (histologically confirmed in 5) and 2 cases without anti-PBC screen antibodies. Patients with chronic hepatitis $\mathrm{B}$ or $\mathrm{C}$ viral infections were excluded. No case of autoimmune hepatitis was diagnosed. All the patients with a clinical/histological diagnosis of PBC were undergoing urso-deoxycholic acid (UDCA) treatment. The Mayo risk score was performed on individual subjects with $\mathrm{PBC}$ at time of liver disease diagnosis in order to determine their survival ${ }^{17}$ and the timing of liver transplantation ${ }^{18}$. Elevation of alkaline phosphatase (ALP; defined as a value 3 -fold higher than normal values) was the best available marker of PBC activity in our cases, as collected from medical records ${ }^{19}$ : elevation of ALP was defined when confirmed in more than 3 consecutive assessments during followup.

Methods. The available sera samples of $201 \mathrm{SSc}$ patients were analyzed by indirect immunofluorescence (IIF) test on HEp-2 cells (Bio-Rad, Hercules, CA, USA) for antinuclear antibodies, including anticentromere (ACA), considered positive at a titer $\geq 1: 80$. Antiextractable nuclear antigen antibodies, namely those directed to topo-1, Ku, PM/Scl, U1RNP, Ro/SSA, La/SSB, Jo-1, Sm, PCNA, ribosomal P, and Ki/SL antigen, were tested by counterimmunoelectrophoresis, using rabbit thymus and human or porcine spleen extracts as substrates ${ }^{20,21,22}$. Anti-RNA polymerase III (RNAPIII) antibodies were tested with a commercial ELISA kit (Inova Diagnostics Inc., San Diego, CA, USA). Anti-Th/To antibodies were tested by RNA immunoprecipitation of K562 cell extract, with urea-PAGE and silver staining (Silver Stain Plus; Bio-Rad) ${ }^{23}$.

AMA were identified by IIF on rodent kidney/stomach/liver tissue sections using anti-human total immunoglobulin antibodies (Kallestad, Chaska, MN, USA), considered positive at titer $>1: 20$. All the 201 sera were analyzed by ELISA (QuantaLite ${ }^{\mathrm{TM}}$ PBC Screen IgG/IgA ELISA, Inova Diagnostics) for antibodies to MIT3, using goat anti-human IgA or anti-human IgG antibodies as secondary antibodies, anti-Sp100, and anti-gp210. All 201 sera were tested by ELISA using a mixture of MIT3, Sp100, and gp210 antigens, called the PBC screen. Positive sera were then tested on individual MIT3, Sp100, and gp210 antigens by ELISA.

Statistical analysis. All the variables were expressed as mean values and SD. The prevalence between groups was compared by Fisher exact test. Student's t or Mann-Whitney U test was used for comparison of levels/values between groups. Statistical significance was accepted at $\mathrm{p}<0.05$.

\section{RESULTS}

Antibodies to at least 1 of MIT3, gp210, or Sp100 (PBC screen) were found in $21 \%(43 / 201)$ of sera. Anti-MIT3 antibodies were detected in $17.9 \%$ (36/201), anti-Sp100 antibodies in 2.5\% (5/201: 3 cases as isolated specificity and 2 cases associated with anti-MIT3), and only 1 serum sample was positive for anti-gp210 (0.5\%). The other 3 sera were positive for the PBC screen, but showed no specificity for individual antigens and were not included in the analysis.

Clinical data of 40 PBC screen-positive and 158 screennegative patients are summarized in Table 1. Mean ages at SSc onset, followup, and mortality were similar between groups. The female:male ratio was 12:1 in the PBC screenpositive group compared to the negative group (5.8:1) but the difference was not statistically significant. A diagnosis of PBC was assessed globally in 8 patients: 6 were PBC screen-positive and 2 were $\mathrm{PBC}$ screen-negative cases. At the time of $\mathrm{PBC}$ diagnosis, patients in both groups showed a low and comparable Mayo risk score. No cases of liver decompensation were detected during followup. A limited cutaneous SSc variant was more common in PBC screenpositive $(80 \%)$ compared to $\mathrm{PBC}$ screen-negative $(63 \%)$ cases $(\mathrm{p}=0.04)$; however, calcinosis was significantly less frequent $(\mathrm{p}=0.012)$ in the PBC screen-positive group. Elevated ALP ( $p<0.0001)$, PBC ( $=0.0024)$, and AMA by immunofluorescence $(\mathrm{p}=0.008)$ were associated with the $\mathrm{PBC}$ screen-positive group.

The most frequent SSc-related autoantibody in the PBC screen-positive group was ACA (55\%), followed by anti-topo-I (20\%). ACA showed a significantly higher

Table 1. Clinical and immunological data of 40 patients with SSc screened for PBC antibodies.

\begin{tabular}{lccc}
\hline & $\begin{array}{c}\text { PBC-positive, } \\
\mathrm{n}=40\end{array}$ & $\begin{array}{c}\text { PBC-negative, } \\
\mathrm{n}=158\end{array}$ & $\mathrm{p}$ \\
Characteristics & $48(11.7)$ & $49.8(14.5)$ & $\mathrm{NS}$ \\
\hline Age at onset, mean (SD) yrs & $13.2(7.2)$ & $12.6(8.3)$ & $\mathrm{NS}$ \\
Followup, mean (SD) yrs & $37 / 3(12: 1)$ & $135 / 23(5.8: 1)$ & $\mathrm{NS}$ \\
Female/male & $12.5(5)$ & $12(19)$ & $\mathrm{NS}$ \\
No. deaths, \% (n) & $80(32)$ & $63(99)$ & 0.04 \\
Limited cutaneous SSc, \% (n) & $42.5(17)$ & $45.5(71 / 156)$ & $\mathrm{NS}$ \\
Skin ulcers, \% (n) & $45(18)$ & $65(95)$ & $\mathrm{NS}$ \\
Telangiectasia, \% (n) & $10(4)$ & $27.6(39 / 141)$ & 0.012 \\
Calcinosis, \% (n) & $77.5(31)$ & $76.9(110 / 143)$ & $\mathrm{NS}$ \\
Esophageal involvement, \% (n) & $35(14)$ & $47(74 / 157)$ & $\mathrm{NS}$ \\
ILD, \% (n) & $20(8)$ & $11(17 / 157)$ & $\mathrm{NS}$ \\
PAH, \% (n) & 0 & $4.4(7 / 157)$ & $\mathrm{NS}$ \\
Renal crisis, \% (n) & $15(6)$ & $1.4(2 / 136)$ & 0.0024 \\
PBC, \% (n) & & \\
Mayo risk score in PBC cases, & & & \\
median (SD) & $4.3(0.4)$ & $4.4(0.9)$ & $\mathrm{NS}$ \\
Elevated ALP (including PBC), & & & \\
$\%$ (n) & $27.5(11)$ & $2(1 / 103)$ & $<0.0001$ \\
AMA,\% (n) & $15.7(6 / 38)$ & $1.3(1 / 78)$ & 0.0088 \\
ACA,\% (n) & $55(22)$ & $27(43 / 157)$ & 0.0013 \\
Anti-topo I, \% (n) & $20(8)$ & $35(55 / 155)$ & $\mathrm{NS}$ \\
Anti-RNAP III, \% (n) & $3.2(1 / 31)$ & $11.5(13 / 113)$ & $\mathrm{NS}$ \\
Anti-Th/To, \% (n) & $5(2)$ & $4(6 / 158)$ & $\mathrm{NS}$ \\
& & & \\
\hline
\end{tabular}

ILD: interstitial lung disease; PAH: pulmonary arterial hypertension; PBC: primary biliary cirrhosis; ALP: alkaline phosphatase; AMA: antimitochondrial antibodies by immunofluorescence; ACA: anticentromere; anti-topo I: antitopoisomerase I; anti-RNAP III: anti-RNA polymerase III; SSc: systemic sclerosis. 
prevalence in the PBC screen-positive group $(\mathrm{p}=0.0013)$. Anti-U1RNP, anti-Ku, anti-Ro/SSA, and anti-RNAPIII antibodies were found in 1 case each.

Since ACA was twice as prevalent in the PBC screenpositive group compared to the screen-negative group, we examined only ACA-positive patients in order to determine whether this clinical association was due to a different prevalence of ACA (Table 2). The same trend was found (reduced telangiectasia and calcinosis; significant increase of ALP, PBC, and AMA), indicating that the association was not due to a different prevalence of ACA between the groups. In contrast, no differences were found between PBC screen-positive and negative subjects when anti-topo-I-positive patients were considered (data not shown). Indeed, PBC was found in 5 cases of ACA-positive/PBC screen-positive, in 1 case of PBC screen-positive, and in 2 cases without $\mathrm{PBC}$ screen or the other SSc-related autoantibodies.

Distributions of PBC, prevalence of elevated ALP in SSc, and different SSc-related autoantibodies are illustrated in Table 3 and Figure 1. PBC screen antibodies were more prevalent in the ACA-positive group, compared with the anti-topo-I-positive group ( $\mathrm{p}=0.068$ ), anti-RNAP III-positive group $(\mathrm{p}=0.05)$, or other autoantiody-positive group $(\mathrm{p}=0.036)$. The diagnosis of $\mathrm{PBC}$ was more frequent in the

Table 2. Comparison of $\mathrm{ACA}+\mathrm{PBC}$ screen-positive (23 cases) and $\mathrm{ACA}+\mathrm{PBC}$ screen-negative (43 cases).

\begin{tabular}{lccc}
\hline Characteristics & $\begin{array}{c}\text { ACA+/PBC } \\
\text { Screen+, n =22 }\end{array}$ & $\begin{array}{c}\text { ACA+/PBC } \\
\text { Screen-, n = 43 }\end{array}$ & $\mathrm{p}$ \\
\hline Skin ulcers & $36.3 \%(8)$ & $40.5 \%(17)$ & $\mathrm{NS}$ \\
Telangiectasias & $50 \%(11)$ & $75 \%(30 / 40)$ & $\mathrm{NS}$ \\
Calcinosis & $13.6 \%(3)$ & $28.2 \%(11 / 39)$ & $\mathrm{NS}$ \\
Esophageal involvement & $81.8 \%(18)$ & $72.5 \%(29 / 40)$ & $\mathrm{NS}$ \\
ILD & $13.6 \% 93)$ & $9.5 \%(4)$ & $\mathrm{NS}$ \\
PAH & $18.2 \%(4)$ & $7 \%(3)$ & $\mathrm{NS}$ \\
Renal crisis & 0 & 0 & $\mathrm{NS}$ \\
Elevated ALP & $36.3 \%(8)$ & $3 \%(1 / 32)$ & 0.002 \\
PBC & $22.7 \%(5)$ & $2.4 \%(1)$ & 0.014 \\
AMA & $30 \%(6 / 20)$ & $2.5 \%(1 / 39)$ & 0.0047 \\
\hline
\end{tabular}

ILD: interstitial lung disease; PAH: pulmonary arterial hypertension; PBC: primary biliary cirrhosis; ALP: alkaline phosphatase; AMA: antimitochondrial antibodies by immunofluorescence; ACA: anticentromere; anti-topo I: antitopoisomerase I; anti-RNAP III: anti-RNA polymerase III.
ACA-positive than the anti-topo-I-positive group ( $\mathrm{p}=$ 0.028). Further, comparing ACA-positive/PBC screen-positive cases with other autoantibody-positive/PBC screen-positive cases, we found more frequent $\mathrm{PBC}[5 / 22(22.7 \%)$ vs $1 / 18(5.5 \%)]$ and PBC and/or ALP elevation [9/22 (40.9\%) vs $3 / 18(16.7 \%)]$ in the former group.

The distribution of different anti-MIT3 isotypes is summarized in Figure 2: isolated IgG anti-MIT3 were found in $16 / 36(44.5 \%)$ sera samples; isolated IgA anti-MIT3 in 12/36 (33.4\%) samples, in 1 case associated with anti-Sp100 antibodies; and IgG+IgA anti-MIT3 in 8/36 (22.3\%) samples, in 1 case with anti-Sp100 antibodies. Anti-Sp100 were found in 5 sera samples: in 3 as an isolated specificity; in 2 cases associated with IgG; and in IgG+IgA anti-MIT3 antibodies in 1 case each. Anti-gp210 antibodies were detected in 1 case.

Clinical associations of different anti-MIT3 isotypes are shown in Table 4. Skin ulcers were observed more frequently in patients with isolated IgG anti-MIT3 compared with the IgA anti-MIT3-positive group ( $\mathrm{p}=0.026$ ). PAH was frequently observed in IgG anti-MIT3-positive cases (31\%) and in $\operatorname{IgG}+\operatorname{IgA}$ anti-MIT3-positive cases (38\%) compared with isolated IgA MIT3-positive $(\mathrm{p}=0.024$ and $\mathrm{p}=0.048$, respectively). No case of PAH was observed in $\operatorname{IgA}$ anti-MIT3-positive, thus this association is specific for IgG class anti-MIT3. The $\mathrm{IgG}+\operatorname{Ig} \mathrm{A}$ anti-MIT3 group appeared to be most closely associated with clinical PBC: the $\operatorname{IgG}+\operatorname{IgA}$ anti-MIT3-positive group showed a more frequent diagnosis of PBC $(50 \%)$ and a more frequent elevation of serum ALP $(62.5 \%)$ compared with other groups $(\mathrm{p}=0.014$ and $\mathrm{p}=$ 0.039 , respectively). AMA were more frequently detected in IgG+IgA anti-MIT3-positive patients $(62.5 \%)$ vs isolated $\operatorname{IgA}(0 \%)$ or $\operatorname{IgG}(13 \% ; \mathrm{p}=0.005$ and $\mathrm{p}=0.0026$, respectively). Within IgG+IgA anti-MIT3-positive patients, ALP elevation was found in 4/5 ACA-positive cases and 1/3 ACA-negative cases. Although diagnosis of $\mathrm{PBC}$ was more frequent in $\operatorname{IgG}+\operatorname{IgA}$ anti-MIT3 cases, we did not observe higher IgM levels in this group, as expected (data not shown).

Anti-MIT3 antibodies by ELISA showed an overall sensitivity and specificity of $75 \%$ and $85.4 \%$, respectively, for the diagnosis of PBC, while AMA (by IIF) showed a lower sensitivity $(62.5 \%)$ and a higher specificity $(97.2 \%)$.

Table 3. PBC screening antibodies and PBC in different SSc-related autoantibodies.

\begin{tabular}{|c|c|c|c|c|c|}
\hline PBC screen,$+ \%$ & $32.8(22 / 67)^{1,2,3}$ & $12.5(8 / 64)^{1}$ & $7(1 / 14)^{2}$ & $25(2 / 8)^{3}$ & $14.5(7 / 48)^{6}$ \\
\hline PBC or elevated ALP, $\%$ & $16.4(11 / 67)^{5}$ & $1.5(1 / 64)^{5}$ & 0 & 0 & $11.7(4 / 34)$ \\
\hline
\end{tabular}

${ }^{1} \mathrm{p}=0.0068 ;{ }^{2} \mathrm{p}=0.053 ;{ }^{3} \mathrm{p}=$ nonsignificant; ${ }^{4} \mathrm{p}=0.028 ;{ }^{5} \mathrm{p}=0.0045 ;{ }^{6} \mathrm{p}=0.036$. PBC: primary biliary cirrhosis; ALP: alkaline phosphatase; ACA: anticentromere; anti-topo I: antitopoisomerase I: anti-RNAP III: anti-RNA polymerase III. 


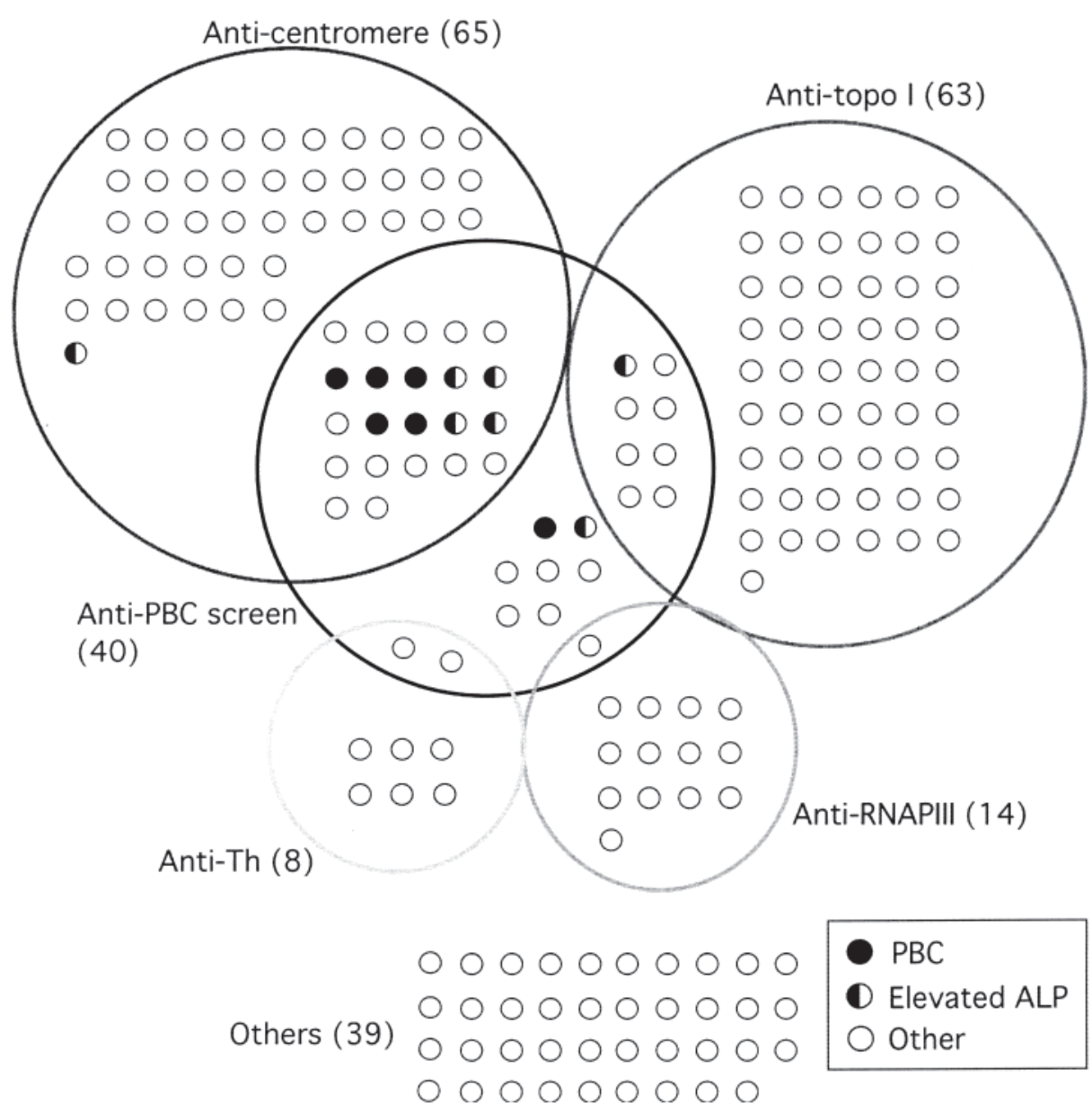

Figure 1. Distribution of primary biliary cirrhosis $(\mathrm{PBC})$ and prevalence of elevated alkaline phosphatase (ALP) in SSc cases with different SSc-related autoantibodies in 201 patients with SSc.

\section{DISCUSSION}

Autoantibodies can be produced in patients years before the clinical onset of disease, as described for anticitrullinated protein antibodies in rheumatoid arthritis or anti-dsDNA in systemic lupus erythematosus ${ }^{24,25}$. Similarly, AMA is considered a specific autoimmune marker of $\mathrm{PBC}$, produced many years before clinical onset of disease ${ }^{4,5}$. However, no direct correlation between AMA and disease severity has been described to date. Although found more rarely, anti-Sp100 and anti-gp210 seem to carry a higher risk for more severe and aggressive $\mathrm{PBC}^{8,9,10,11}$. AMA are usually detected using the IIF test on rodent tissue extracts, while anti-Sp100 and anti-gp210 can be detected by line immunoassays on recombinant antigens ${ }^{26}$ or less readily available tests, such as immunoprecipitation on purified rat liver nuclear membrane as antigen source ${ }^{27}$. An ELISA with the 3 major antigens for AMA (namely, anti-MIT3), Sp100, and gp210 seemed to enhance the sensitivity and specificity for the diagnosis of isolated $\mathrm{PBC}^{28}$ or PBC-SSc overlap $^{2}$. Nevertheless, the prognostic value of these autoantibodies detected by ELISA has not been established in $\mathrm{PBC}$ to date.

Anti-MIT3, anti-gp210, and Sp100 antibodies (the PBC screen) were found globally in $21.4 \%$ of our cohort of 201 unselected SSc cases, while anti-MIT3 antibodies were detected in $18 \%$ of cases. These autoantibodies have been described in SSc without clinical or biochemical signs of autoimmune liver disease ${ }^{28,29,30}$. Although the prevalence of PBC screen antibodies in our patients with SSc was similar to the prevalence reported by others ${ }^{2,29}$, a diagnosis of PBC was determined more frequently in our cohort. Indeed, $\mathrm{PBC}$ was diagnosed in $14 \%$ of PBC screen-positive patients and in only $1.3 \%$ of screen-negative patients $(\mathrm{p}=0.0009)$. Among PBC screen antibodies, anti-MIT3 showed a high sensitivity $(6 / 8 ; 75 \%)$ and specificity $(85.4 \%)$ for the diagnosis of $\mathrm{PBC}$, confirming previous reports ${ }^{2}$. By contrast, the occurrence of anti-Sp100 antibodies or anti-gp210 did not confer any additional value to anti-MIT3 for the diagnosis of $\mathrm{PBC}$, probably because of the small number of positive sera samples in our cohort. 



Figure 2. Associations among primary biliary cirrhosis (PBC) and various anti-MIT3 isotype antibodies.

Table 4. Clinical and laboratory features in 36 patients with positive SSc for anti-MIT3 antibodies.

\begin{tabular}{lcc}
\hline Characteristic & $\begin{array}{c}\text { IgG+IgA Anti-MIT3, } \\
\mathrm{n}=8\end{array}$ & $\begin{array}{c}\operatorname{IgG} \text { or IgA Anti-MIT3, } \\
\mathrm{n}=28\end{array}$ \\
\hline Female/male & $7 / 1$ & $26 / 2$ \\
Skin ulcers*, \% (n) & $25(2)$ & $46.4(13)$ \\
ILD, \% (n) & $25(2)$ & $35.7(10)$ \\
PAH**,\% (n) & $37.5(3)$ & $53.6(5)$ \\
ACA, \% (n) & $62.5(5)$ & $50(14)$ \\
Anti-topo I, \% (n) & $12.5(10$ & $21.4(6)$ \\
AMA***, \% (n) & $62.5(5)$ & $7.7(2 / 26)$ \\
Elevated ALP & $62.5(5)$ & $21.4(6)$ \\
PBC & $50(4)$ & $7(2)$
\end{tabular}

* Skin ulcers: isolated IgG anti-MIT3 (62.5\%) vs isolated IgA (25\%): p = 0.05 , Fisher test. ** PAH: isolated IgG anti-MIT3 (31\%) vs isolated IgA $(0 \%): p=0.024$, Fisher test. ${ }^{\dagger}$ Elevated ALP: $\operatorname{IgG}+\operatorname{IgA}$ anti-MIT3 $(62.5 \%)$ vs isolated $\operatorname{IgA}(16 \%)$ : p $=0.0054, \operatorname{IgG}+\operatorname{IgA}$ anti-MIT3 $(62.5 \%)$ vs other groups (21.4\%): $\mathrm{p}=0.039$. *** AMA: IgG+IgA anti-MIT3 (62.5\%) vs isolated $\operatorname{IgA}(0 \%): p=0.005$ vs isolated $\operatorname{IgG}(13 \%): p=0.0025$ vs other groups (7.7\%): $\mathrm{p}=0.0035$. ${ }^{\dagger} \mathrm{PBC}: \operatorname{IgG}+\operatorname{IgA}$ anti-MIT3 (50\%) vs isolated $\operatorname{IgG}(6 \%): p=0.027$ vs isolated $\operatorname{IgA}(8 \%): \mathrm{p}=0.05$ vs other groups $(7 \%)$ : $\mathrm{p}=0.014$. ILD: interstitial lung disease; $\mathrm{PAH}$ : pulmonary arterial hypertension; ACA: anticentromere; anti-topo I: antitopoisomerase I; AMA: antimitochondrial antibodies by immunofluorescence; ALP: alkaline phosphatase; PBC: primary biliary cirrhosis; SSc: systemic sclerosis.
Analyzing the isotypes of anti-MIT3 antibodies, IgG+IgA anti-MIT3 showed a significant association with the diagnosis of PBC ( $p=0.014)$ and AMA ( $p=0.0035)$ compared with other groups. The occurrence of anti-MIT3 of the $\operatorname{IgG}$ and $\operatorname{IgA}$ isotypes, with no evidence of elevation of total circulating IgG or IgA levels, may be consistent with the immune system affinity maturation and class switching toward specific mitochondrial antigens rather than simple polyclonal B cell activation. Indeed, specific antipyruvate dehydrogenase complex IgA have been described in PBC, in circulation or localized in the apical surface and in the cytoplasm of biliary epithelial cells ${ }^{7}$. Moreover, AMA-IgA seems to possess a direct toxic effect on biliary epithelium ${ }^{31}$, contributing to the complex pathogenesis of bile duct damage in $\mathrm{PBC}^{7}$.

The occurrence of $\operatorname{IgG}+\operatorname{IgA}$ anti-MIT3 antibodies was associated with persistent elevation of ALP in our series. High ALP value, along with increased bilirubin and reduced serum albumin, is considered a very sensitive indicator of disease severity, poor response to UDCA treatment, and progression to liver failure in $\mathrm{PBC}^{15,19,31,32}$. Some investigators have reported a significant association between ALP elevation and ACA or anti-topo-I antibodies, independent from AMA or anti-Sp100 status ${ }^{2}$. By contrast, presence of anti-RNAPIII antibodies was associated with lower ALP levels ${ }^{2}$. In our experience ALP elevation is associated with IgG+IgA anti-MIT3 antibodies, independent from ACA or anti-topo-I positivity.

Most of the AMA-positive sera samples (7/8) showed anti-MIT3 antibodies. Although time-consuming, the IIF assay using rodent tissue sections as substrate is considered the gold standard for detection of $\mathrm{AMA}^{33}$. This test showed a lower specificity and sensitivity compared with Western blot or ELISA tests ${ }^{34}$, with good performance when compared with the line immunoassay 26 .

The availability of fully automated ELISA testing could enhance investigation of various autoantibodies that are considered markers of PBC in routine laboratory analysis, avoiding the use of different assays with diversified antigen sources. In addition, given the specific association between $\mathrm{PBC}$ and $\operatorname{IgG}+\operatorname{IgA}$ anti-MIT3, characterization of the isotype specificity could be helpful for more accurate assessment of patients. Further studies are needed to clarify the possible association between the development of $\mathrm{PBC}$ and the anti-MIT3 antibodies in $\operatorname{IgG}$ vs $\operatorname{IgG}+\operatorname{IgA}$ classes.

\section{REFERENCES}

1. Avouac J, Airò P, Dieude P, Caramaschi P, Tiev K, Diot E, et al. Associated autoimmune diseases in systemic sclerosis define a subset of patients with milder disease: results from 2 large cohorts of European Caucasian patients. J Rheumatol 2010;37:608-14.

2. Assassi S, Fritzler MJ, Arnett FC, Norman GL, Shah KR, Gourh P, et al. Primary biliary cirrhosis (PBC), $\mathrm{PBC}$ autoantibodies, and hepatic parameter abnormalities in a large population of systemic sclerosis patients. J Rheumatol 2009;36:2250-6.

3. Rigamonti C, Shand LM, Feudjo M, Bunn CC, Black CM, Denton 
$\mathrm{CP}$, et al. Clinical features and prognosis of primary biliary cirrhosis associated with systemic sclerosis. Gut 2006;55:388-94.

4. Kaplan MM, Gershwin ME. Primary biliary cirrhosis. N Engl J Med 2005;353:1261-73.

5. Gershwin ME, Ansari AA, MacKay IR, Nakanuma Y, Nishio A, Rowley MJ, et al. Primary biliary cirrhosis: an orchestrated immune response against epithelial cells. Immunol Rev 2000;174:210-25.

6. Miyakawa H, Tanaka A, Kikuchi K, Matsushita M, Kitazawa E, Kawaguchi N, et al. Detection of antimitochondrial autoantibodies in immunofluorescent AMA-negative patients with primary biliary cirrhosis using recombinant autoantigens. Hepatology 2001; 34:243-8.

7. Selmi C, Zuin M, Bowleus CL, Gershwin ME. Anti-mitochondrial antibody-negative primary biliary cirrhosis. Clin Liver Dis 2008;12:173-85.

8. Lleo A, Invernizzi P, Mackay IR, Prince H, Zhong RQ, Gershwin ME. Etiopathogenesis of primary biliary cirrhosis. World J Gastroenterol 2008;14:3328-37.

9. Miyachi K, Hankins RW, Matsushima H, Kikuchi F, Inomata T, Horigome T, et al. Profile and clinical significance of anti-nuclear envelope antibodies found in patients with primary biliary cirrhosis: a multicenter study. J Autoimmun 2003;20:247-54.

10. Itoh S, Ichida T, Yoshida T, Hayakawa A, Uchida M, Tashiro-Itoh $\mathrm{T}$, et al. Autoantibodies against a $210 \mathrm{kDa}$ glycoprotein of the nuclear pore complex as a prognostic marker in patients with primary biliary cirrhosis. J Gastroenterol Hepatol 1998;13:257-65.

11. Invernizzi P, Selmi C, Ranftler C, Podda M, Wesierska-Gadek J. Antinuclear antibodies in primary biliary cirrhosis. Semin Liver Dis 2005;25:298-310.

12. Moteki S, Leung PS, Coppel RL, Dickson ER, Kaplan MM, Munoz $\mathrm{S}$, et al. Use of a designer triple expression hybrid clone for three different lipoyl domains for the detection of antimitochondrial autoantibodies. Hepatology 1996;24:97-103.

13. Preliminary criteria for the classification of systemic sclerosis (scleroderma). Subcommittee for scleroderma criteria of the American Rheumatism Association Diagnostic and Therapeutic Criteria Committee. Arthritis Rheum 1980;23:581-90.

14. LeRoy EC, Black C, Fleischmajer R, Jablonska S, Krieg T, Medsger TA Jr, et al. Scleroderma (systemic sclerosis): classification subsets and pathogenesis. J Rheumatol 1988;15:202-5.

15. Valentini G, Medsger TA Jr, Silman AJ, Bombardieri S, editors. The assessment of the patient with systemic sclerosis. Clin Exp Rheumatol 2003;21 Suppl 29:S1-S56.

16. EASL Clinical Practice Guidelines: management of cholestatic liver diseases. J Hepatol 2009;51:237-67.

17. Dickson ER, Grambsch PM, Fleming TE, Fisher LD, Langworthy A. Prognosis in primary biliary cirrhosis: model for decision making. Hepatology 1989;10:1-7.

18. Kim WR, Wiesner RH, Therneau TM, Poterucha JJ, Porayko MK, Evans RW, et al. Optimal timing of liver transplantation for primary biliary cirrhosis. Hepatology 1998;28:33-8.

19. Corpechot C, Abenavoli L, Rabahi N, Chretiwn Y, Andreani T, Johanet C, et al. Biochemical response to ursodeoxycholic acid and long-term prognosis in primary biliary cirrhosis. Hepatology 2008;48:871-7.
20. Bernstein RM, Bunn CC, Hughes GRV. Identification of antibodies to acidic antigens by counterimmunoelectrophoresis. Ann Rheum Dis 1982;41:554-5.

21. Clark G, Reichlin M, Tomasi TB. Characterization of a soluble cytoplasmic antigen reactive with sera from patients with systemic lupus erythematosus. J Immunol 1969;102:117-22.

22. Venables PJW, Smith PR, Maini RN. Purification and characterization of the Sjögren's syndrome A and B antigens. Clin Exp Immunol 1983;54:731-8.

23. Verheijen R, Wiik A, De Jong BAW, Hoier-Madsen M, Ullman S, Halberg P, et al. Screening for autoantibodies to the nucleolar U3-and Th(7-2) ribonucleoproteins in patients' sera using antisense riboprobes. J Immunol Methods 1994;169:173-82.

24. van Venrooij WJ, Zendman AJW, Pruijn GJM. Autoantibodies to citrullinated antigens in (early) rheumatoid arthritis. Autoimmun Rev 2006;6:37-41.

25. Arbuckle MR, McClain MT, Rubertone MV, Scofield RH, Dennis GJ, James JA, et al. Development of autoantibodies before the clinical onset of systemic lupus erythematosus. N Engl J Med 2003;349:1526-33.

26. Stinton LM, Swain M, Myers RP, Shaheen AA, Fritzler MJ. Autoantibodies to GW bodies and other autoantigens in primary biliary cirrhosis. Clin Exp Immunol 2010;163:147-56.

27. Favreau C, Bastos R, Cartaud J, Courvalin JC, Mustonen P. Biochemical characterization of nuclear pore complex protein gp210 oligomers. Eur J Biochem 2001;268:3883-9.

28. Dähnrich C, Pares A, Caballeria L, Rosemann A, Schlumberger W, Probst C, et al. New ELISA for detecting primary biliary cirrhosis-specific antimitochondrial antibodies. Clin Chem 2009;55:978-85.

29. Norman GL, Bialek A, Ancabo S, Butkiewcz B, Wiechowska-Kozlowska A, Brzosko M, et al. Is prevalence of PBC underestimated in patients with systemic sclerosis? Dig Liver Dis 2009;41:762-4.

30. Mytilinaiou MG, Bogdanos DP. Primary biliary cirrhosis-specific autoantibodies in patients with systemic sclerosis. Dig Liver Dis 2009;41:914-7.

31. Matsumura S, van de Water J, Leung P, Odin JA, Yamamoto K, Gores JD, et al. Caspase induction by IgA antimitochondrial antibodies: IgA-mediated biliary injury in primary biliary cirrhosis. Hepatology 2004;39:1415-22.

32. Hohenester S, Oude-Elferink RPJ, Beuers U. Primary biliary cirrhosis. Semin Immunopathol 2009;31:283-307.

33. Vergani D, Alvarez F, Bianchi FB, Cancado EL, Mackay IR, Manns MP, et al. Liver autoimmune serology: a consensus statement from the committee for autoimmune serology of the International Autoimmune Hepatitis Group. J Hepatol 2004;41:677-83.

34. Muratori P, Muratori L, Gershwin ME, Czaja AJ, Pappas G, MacCariello S, et al. 'True' antimitochondrial antibody-negative primary biliary cirrhosis, low sensitivity of the routine assays, or both? Clin Exp Immunol 2004;135:154-8. 